\title{
Lifetime co-morbidities between social phobia and mood disorders in the US National Comorbidity Survey
}

\author{
R. C. KESSLER, ${ }^{1}$ P. STANG, H.-U. WITTCHEN, M. STEIN AND E. E. WALTERS \\ From the Department of Health Care Policy, Harvard Medical School, Boston, MA, Department of \\ Epidemiology, University of North Carolina, SmithKline-Beecham, NC and Department of Psychiatry, \\ University of California, San Diego, CA, USA; and Department of Clinical Psychology, Max Planck \\ Institute of Psychiatry, Munich, Germany
}

\begin{abstract}
Background. General population data were used to study co-morbidities between lifetime social phobia and mood disorders.

Methods. Data come from the US National Comorbidity Survey (NCS).

Results. Strong associations exist between lifetime social phobia and major depressive disorder (odds ratio 2.9), dysthymia (2.7) and bipolar disorder (5.9). Odds ratios increase in magnitude with number of social fears. Reported age of onset is earlier for social phobia than mood disorders in the vast majority of co-morbid cases. Temporally-primary social phobia predicts subsequent onset of mood disorders, with population attributable risk proportions of $10-15 \%$. Social phobia is also associated with severity and persistence of co-morbid mood disorders.

Conclusions. Social phobia is a commonly occurring, chronic and seriously impairing disorder that is seldom treated unless it occurs in conjunction with another co-morbid condition. The adverse consequences of social phobia include increased risk of onset, severity and course of subsequent mood disorders. Early outreach and treatment of primary social phobia might not only reduce the prevalence of this disorder itself, but also the subsequent onset of mood disorders.
\end{abstract}

\section{INTRODUCTION}

Psychiatric co-morbidity is highly prevalent among patients with mood disorders (Liebowitz et al. 1985; Alpert et al. 1994) and is associated with impairment and chronicity (Hecht et al. 1989; Wittchen \& Essau, 1989). Co-morbid anxiety has received the most attention in this regard (Maser \& Cloninger, 1990), with panic (Reich et al. 1993; Kessler et al. 1998a) and generalized anxiety disorder (Noyes et al. 1992; Brawman-Mintzer et al. 1993) being the subjects of special interest based on their strong associations with mood disorders. However, social phobia (sometimes referred to as social

1 Address for correspondence: Professor Ronald C. Kessler, Department of Health Care Policy, Harvard Medical School, 180 Longwood Avenue, Boston, MA 02115, USA. anxiety), the most commonly occurring anxiety disorder among people with mood disorders (Kessler, 1995; Merikangas et al. 1996), has been comparatively neglected in research on comorbid mood disorders. This is presumably due to the fact that social phobia is under diagnosed (Liebowitz et al. 1985; Weiller et al. 1996; Fones et al. 1998) and incorrectly regarded as not seriously impairing (Judd, 1994; Hirschfeld, 1995; Wittchen \& Beloch, 1996). The current report helps address this oversight by presenting epidemiological data on co-morbidity between mood disorders and social phobia in the US National Comorbidity Survey (NCS; Kessler et al. 1994).

Previous studies have documented that social phobia is significantly co-morbid with mood disorders (Schneier et al. 1992; Lecrubier \& Weiller, 1997; Pini et al. 1997) and that social 
phobia is temporally primary in the vast majority of these cases (Merikangas et al. 1996; Parker et al. 1997). Social phobia has also been linked to severity (Merikangas \& Angst, 1995) and persistence (Alpert et al. 1997) of mood disorders. We expand the investigation of these issues here in a number of ways. First, unlike many previous studies, we control for other co-morbid conditions in order to provide a clear evaluation of the unique effects of social phobia on mood disorders. Secondly, we introduce a number of specifications aimed at disentangling contending interpretations of previously documented findings. Thirdly, unlike most previous studies (for notable exceptions, see Angst, 1996 and Pini et al. 1997), we present data separately on major depressive disorder, dysthymia and bipolar disorder in order to examine whether patterns and correlates of co-morbidity vary across types of mood disorder.

Four logical possibilities exist for explaining the co-morbidity between mood disorders and social phobia: that social phobia is a causal risk factor for secondary mood disorders, that mood disorders are risk factors for secondary social phobia, that social phobia and mood disorders are both consequences of some common cause, and that methodological factors create an artificial association between the two disorders. Most clinical research has focused on the first possibility. It has been postulated that persistent anxiety leads to an exhaustion response that eventually results in depression (Akiskal, 1990). This supposition is at least superficially consistent with two findings: (1) most patients with a history of both disorders report that their social phobia preceded the depression; and (2) social phobia was a strong predictor of subsequent depression in one prospective study (Angst, 1996). Another prospective study documented a weaker predictive association (Parker et al. 1997).

If this causal interpretation were correct, we would expect a dose-response relationship between temporally-primary social phobia and the subsequent onset, course, and severity of secondary mood disorders. Data on this possibility are presented here that distinguish between the large group of social phobics found in previous NCS analyses to have exclusive performance fears associated with public speaking and others who have a more generalized form of social phobia (Kessler et al. 1998b). If secondary depression was a consequence of prior social phobia, we would expect the more generalized form of social phobia to more powerfully predict onset, course and severity of secondary mood disorders.

Furthermore, if secondary mood disorders were the result of exhaustion or demoralization in the face of persistent and intractable anxiety, we would expect that chronic anxiety not merely occasional anxiety precipitates secondary mood disorders. Risk of mood disorders would expectedly increase with the duration of the social phobia. If social phobia is a genuine risk factor we would also expect that only currently active social phobia not remitted social phobia would predict the subsequent onset, course, and severity of secondary mood disorders. If, on the other hand, social phobia is a marker of risk rather than a true risk factor (Kraemer et al. 1997), remitted social phobia might continue to elevate risk of mood disorders. The same pattern might exist if social phobia is a phase in a distinct biologically determined anxiety-mood disorder. All of these specifications are examined in the present report.

\section{METHOD}

\section{Sample}

The NCS is a nationally representative household survey of persons ages 15 to 54 in the noninstitutionalized civilian population of the 48 coterminous United States along with a representative supplemental sample of students living in campus group housing. The NCS was administered to 8098 respondents between 14 September 1990 and 6 February 1992 in face-toface in-home interviews. The response rate was $82.4 \%$. The data reported here have been weighted to adjust for differential probabilities of selection and non-response. Additional details of the NCS design, field procedure and sample weights are reported elsewhere (Kessler et al. 1994, 1995a).

\section{Diagnostic assessment}

NCS diagnoses are based on a modified version of the Composite International Diagnostic Interview (CIDI; WHO, 1990), a fully structured interview designed to be administered by interviewers who are not clinicians and to generate 
diagnoses according to the definitions and criteria of both DSM-III-R (APA, 1987) and ICD-10 (WHO, 1991). DSM-III-R criteria are used in the current report. The disorders of primary interest are social phobia, major depressive disorder, dysthymia and bipolar disorder. However, we also control for comorbidities with the other DSM-III-R disorders assessed in the NCS, including other anxiety disorders (panic disorder, other phobias, generalized anxiety disorder, post-traumatic stress disorder), substance use disorders (alcohol and drug abuse and dependence) and nonaffective psychosis. Results for these controls are not reported in the tables in order to avoid undue complexity. However, detailed data on the magnitude of co-morbidities among all the NCS disorders are reported elsewhere (Kessler, 1997).

An NCS clinical reappraisal study of the CIDI was carried out (Kessler et al. 1998c) that found good test-retest reliability for all diagnoses and good validity compared to blind clinical reinterviews for all diagnoses with the exceptions of mania (Kessler et al. 1997) and non-affective psychosis (NAP; Kendler et al. 1996). In the case of mania, we found that the CIDI had great difficulty accurately classifying respondents who reported irritability rather than euphoria as their master symptom, while the subset of cases with a euphoric-grandiose symptom profile were classified with very good accuracy. Therefore, only the subset of respondents with a euphoric-grandiose symptom profile were classified as having bipolar disorder for the purposes of this report. In the case of NAP, we found that the judgements about presumed delusions required to be made by lay interviewers based on open-ended reports of respondents had very low clinical validity. Therefore, clinical reinterviews were attempted with all respondents classified as having NAP by the CIDI to confirm the diagnoses.

As separate clinical reappraisal interviews were carried out for each diagnosis and diagnostic hierarchy rules were not used in carrying out the clinical reappraisal interviews, no data are available on the CIDI's accuracy in discriminating between unipolar and bipolar depression or between depression and panic in the NCS. The absence of such data is a limitation of these results.
Earlier WHO CIDI field trials found only marginally acceptable validity compared to clinician assessments of retrospective diagnostic age of onset reports (Wittchen et al. 1989). This is an important limitation because age of onset plays a central role in the analysis of temporal priorities between lifetime co-morbid disorders. In order to improve the accuracy of these reports in the NCS, the standard CIDI age of onset question, which simply asks respondents how old they were when they first had an episode of depression or a panic attack or a cluster of four panic attacks in a single month, was elaborated into a series of three more focused questions. The first question asked respondents if they could 'CLEARLY REMEMBER (emphasis in original)' the exact age when they had their first episode or attack or attack cluster. If so, that age was recorded. If not, they were asked their approximate age at onset: 'ABOUT (emphasis in original) how old were you the first time?'. They were then asked for 'the earliest age you can CLEARLY REMEMBER (emphasis in original)' a particular episode or attack or attack cluster. The response to this last question was taken as an upper bound on the respondent's age of onset. In the case of respondents who reported multiple social fears, age of onset was dated for the earliest of these fears.

No data to assess the comparative validity of the age of onset reports based on this threequestion series were obtained in the NCS clinical reappraisal study. However, the substantively implausible associations between age at interview and reported age of onset found in surveys that use the standard CIDI age of onset question (Simon \& VonKorff, 1995) does not exist in the NCS (Knauper et al. 1999), indirectly arguing for an improvement in validity based on the use of the more complex age of onset questions. Nonetheless, the likely existence of remaining error in NCS retrospective age of onset reports should be considered a limitation of these results.

\section{Analysis procedures}

The CIDI includes questions about six social phobia trigger situations: speaking in public; having to use the toilet when away from home, eating or drinking in public; talking to people when you might have nothing to say or might sound foolish; writing while someone watches; 
and talking in front of a small group of people ('small' was not defined). A previously reported latent class analysis of the multivariate associations among these fears found two social phobia latent classes: one characterized by pure speaking fears (endorsement of only the first and/or last of the six items); and another characterized by a more general set of social fears (Kessler et al. 1998 b). Based on this finding, the results reported below distinguish between social phobics with pure speaking fear $(35.8 \%$ of all social phobics in the NCS) and other social phobics $(64 \cdot 2 \%)$. Within the subsample of social phobics with pure speaking fears, we also distinguish between those who have an exclusive fear of public speaking $(21.8 \%$ of all social phobics), which is by far the most common exclusive social fear, and those who also have a fear of speaking in small groups $(14.0 \%)$. Within the subsample of social phobics with other social fears, we distinguish between those who have only one fear $(8.5 \%)$, two fears $(15.9 \%)$, and three or more fears $(39 \cdot 6 \%)$.

Conditional probabilities and odds-ratios were used to study co-morbidity. Retrospective age of onset reports were used to study temporal priorities between first onsets. Discrete-time survival analysis with person-year as the unit of analysis was used to study predictive associations between temporally primary social phobia and secondary mood disorders. In this method, each year in the life of each respondent up to and including the year of onset of the mood disorder or the year of interview, whichever comes first, is treated as a separate observational record. Logistic regression was used to predict a dichotomous measure of onset of the outcome disorder (coded one for the year of onset and zero for prior years) in this person-year file. When controls are introduced for age at time of the observational record, the logistic regression coefficients can be interpreted as survival coefficients in a model that allows nonproportional hazards (Efron, 1988). These coefficients can also be exponentiated to generate odd ratios (ORs). The predictors can be either unrelated to time, such as gender or race, or time-varying, such as marital status or history of other disorders.

In our use of the discrete-time survival method, we estimated a separate series of models to predict lifetime first onset of three outcomes: major depressive disorder, dysthymia and bipolar disorder. In each model we included controls for age in the person-year, age at interview, gender and race. The predictors of primary interest were time-varying measures of the prior onset and continuation of social phobia. These were 'time-varying' in that they were coded as not present for the observational records for a particular respondent up to the age of onset of social phobia and then coded as present in subsequent observational records. We also elaborated this coding to create predictor variables that indicated how many years it had been since first onset of social phobia. We used respondent reports about age of recency of social phobia to create predictor variables that distinguished observational records characterized by a history of remitted social phobia and active social phobia. Controls for other comorbid DSM-III-R disorders in the NCS that had onsets prior to or in the same year as social phobia were also included in the equations.

Significant tests for individual ORs were computed using the method of jackknife repeated replications (JRR; Kish \& Frankel, 1974) to estimate standard errors that adjusted for design effects introduced by clustering and weighting of observations. JRR is one of several methods that use simulations of coefficient distributions in subsamples to generate empirical estimates of standard errors and significance tests. The ratios of the coefficients to these adjusted standard errors were used to compute $z$ tests for the significance of the survival coefficients and $95 \%$ confidence intervals for the ORs. Tests for the significance of sets of predictors taken together were computed using Wald chi-square tests from coefficient variance-covariance matrices based on the JRR simulations.

\section{RESULTS}

\section{Co-morbidities between social phobia and mood disorders}

The lifetime (LT) prevalence of DSM-III-R social phobia and mood disorders in the NCS have been reported previously (Kessler et al. 1994, 1997, 1998b). They include 13.3\% for social phobia, $14.9 \%$ for major depressive disorder, $2.8 \%$ for dysthymia, $0.4 \%$ for the euphoric-grandiose subtype of bipolar disorder 
Table 1. The lifetime prevalences of social phobia among NCS respondents with lifetime mood disorders

\begin{tabular}{|c|c|c|c|c|c|c|c|c|c|c|c|c|}
\hline & \multicolumn{2}{|c|}{ Major depression } & \multicolumn{3}{|c|}{ Dysthymia } & \multicolumn{3}{|c|}{ Bipolar disorder } & \multicolumn{2}{|c|}{ Any mood disorder } & \multicolumn{2}{|c|}{ Total sample } \\
\hline & $\% \dagger$ & $\mathrm{OR}+(95 \% \mathrm{CI})$ & $\% \dagger$ & $\mathrm{OR}+$ & $(95 \% \mathrm{CI})$ & $\% \dagger$ & OR: & $(95 \% \mathrm{CI})$ & $\% \dagger$ & OR $+(95 \% \mathrm{CI})$ & $\%$ & $(N)$ \\
\hline \multicolumn{13}{|l|}{ Pure speaking phobia } \\
\hline Public speaking only & $5 \cdot 0$ & $2 \cdot 4 * \quad(1.5-3 \cdot 6)$ & $3 \cdot 1$ & $1 \cdot 3$ & $(0 \cdot 5-3 \cdot 6)$ & $0 \cdot 0$ & - & $(-)$ & $4 \cdot 4$ & $2 \cdot 0 * \quad(1 \cdot 3-3 \cdot 1)$ & $2 \cdot 9$ & 236 \\
\hline Broader speaking fears & $4 \cdot 0$ & $3 \cdot 2 * \quad(1 \cdot 8-5 \cdot 6)$ & $2 \cdot 6$ & $1 \cdot 7$ & $(0 \cdot 6-4 \cdot 8)$ & $0 \cdot 0$ & - & $(-)$ & $3 \cdot 8$ & $3 \cdot 1 * \quad(1 \cdot 8-5 \cdot 4)$ & 1.9 & 151 \\
\hline Total & $9 \cdot 0$ & $2 \cdot 7^{*} \quad(1 \cdot 8-4 \cdot 0)$ & $5 \cdot 7$ & $1 \cdot 5$ & $(0 \cdot 7-3 \cdot 0)$ & $0 \cdot 0$ & - & $(-)$ & $8 \cdot 1$ & $2 \cdot 4 * \quad(1 \cdot 6-3 \cdot 6)$ & $4 \cdot 8$ & 387 \\
\hline \multicolumn{13}{|l|}{ Other social phobia } \\
\hline 1 fear & $2 \cdot 5$ & $3 \cdot 4 * \quad(1 \cdot 7-6 \cdot 9)$ & $1 \cdot 3$ & $1 \cdot 4$ & $(0 \cdot 4-5 \cdot 1)$ & $5 \cdot 3$ & $7 \cdot 9 *$ & $(2 \cdot 0-31 \cdot 6)$ & $2 \cdot 4$ & $3 \cdot 4 * \quad(1 \cdot 8-6 \cdot 7)$ & $1 \cdot 1$ & 92 \\
\hline 2 fears & $4 \cdot 0$ & $2 \cdot 7 * \quad(1 \cdot 8-4 \cdot 1)$ & $5 \cdot 1$ & $3 \cdot 1^{*}$ & $(1 \cdot 6-6 \cdot 0)$ & $8 \cdot 2$ & $6 \cdot 4^{*}$ & $(1 \cdot 6-26 \cdot 3)$ & $4 \cdot 0$ & $2 \cdot 8 * \quad(1.8-4.3)$ & $2 \cdot 1$ & 171 \\
\hline$\geqslant 3$ or more fears & $11 \cdot 0$ & $3 \cdot 1 * \quad(2 \cdot 4-4 \cdot 0)$ & $16 \cdot 4$ & $4 \cdot 0^{*}$ & $(2 \cdot 4-6 \cdot 9)$ & $33 \cdot 6$ & $10 \cdot 7 *$ & $(2 \cdot 7-42 \cdot 3)$ & $12 \cdot 1$ & $3 \cdot 8 * \quad(3 \cdot 0-4 \cdot 8)$ & $5 \cdot 3$ & 428 \\
\hline Total & $17 \cdot 5$ & $3 \cdot 0 * \quad(2 \cdot 4-3 \cdot 8)$ & $22 \cdot 8$ & $3 \cdot 4^{*}$ & $(2 \cdot 1-5 \cdot 4)$ & $47 \cdot 1$ & $9 \cdot 3^{*}$ & $(2 \cdot 8-30 \cdot 6)$ & $18 \cdot 5$ & $3 \cdot 5^{*} \quad(2 \cdot 8-4 \cdot 2)$ & $8 \cdot 5$ & 691 \\
\hline Any social phobia & $26 \cdot 5$ & $2 \cdot 9 * \quad(2 \cdot 3-3 \cdot 6)$ & $28 \cdot 5$ & $2 \cdot 7 *$ & $(1 \cdot 9-3 \cdot 8)$ & $47 \cdot 1$ & $5 \cdot 9 *$ & $(1 \cdot 8-19 \cdot 6)$ & $26 \cdot 6$ & $3 \cdot 1 * \quad(2 \cdot 5-3 \cdot 8)$ & $13 \cdot 3$ & 1078 \\
\hline
\end{tabular}

* Significant at the $0 \cdot 05$ level.

$\dagger$ The percentage columns report the lifetime prevalences of social phobia among respondents with a history of mood disorders. For example, the $5 \%$ in the upper left corner of the table means that $5 \%$ of the NCS respondents with a lifetime history of major depression also had a history of pure public speaking social phobia.

\$ The OR columns report odds ratios between lifetime social phobia and mood disorders. Entries for subtypes exclude other subtypes from the calculations. For example, the $2 \cdot 4$ odds ratio between pure public speaking social phobia and major depression excludes respondents with other social phobia subtypes.

and $17 \cdot 1 \%$ for any mood disorder. We also consider social phobia subtypes, including respondents who report exclusive social fears associated with public speaking $(2.9 \%$ of the population) broader speaking fears $(1.9 \%)$ and types with either one $(1 \cdot 1 \%)$, two $(2 \cdot 1 \%)$, or three or more $(5.3 \%)$ social fears not exclusively involving speaking in the CIDI.

As shown in Table 1, somewhat more than one-quarter of respondents with lifetime major depression $(26.5 \%)$ or dysthymia $(28.5 \%)$ and nearly half of those with bipolar disorder $(47 \cdot 1 \%)$ also meet lifetime criteria for social phobia. Although the results in the table are not percentaged from the perspective of mood disorders, transformation shows that $34.2 \%$ of lifetime social phobics reported a lifetime mood disorder compared to $14.5 \%$ of respondents who did not have social phobia. The ORs between social phobia and lifetime mood disorders are 2.9 for major depression, 2.7 for dysthymania and a substantially higher 5.9 for bipolar disorder. ORs are consistently lowest for social phobia associated with pure fear of public speaking. It is noteworthy that the pure public speaking OR with any mood disorder (2.0) is considerably less than the odds ratio associated with other pure social fears (3.4), indicating that it is not merely having only one social fear, but also the nature of that fear, that is relevant for co-morbidity with mood disorders. It is further noteworthy that there are no cases of pure speaking phobia among bipolars. Given the higher prevalence of social phobia and mood disorders among women than men in the NCS (Kessler et al. 1994), we tested for sex differences in the odds ratios reported in Table 1. None of the 29 odds ratios was found to differ significantly by sex at the 0.05 level of significance (results not shown).

\section{Temporal priority between social phobia and mood disorders}

Retrospective age of onset reports were compared to assess the temporal priority of first onsets of social phobia and mood disorder. As shown in Table 2, $68.5 \%$ of respondents with a history of both said the social phobia occurred at an earlier age than the mood disorder compared to $21.9 \%$ who said the mood disorder occurred at an earlier age than the social phobia. The remainder reported onsets of both disorders at the same age. The mean of the absolute value of the difference in ages of onset among all respondents with a history of both social phobia and a mood disorder was 7.2 years (with a standard error of 0.8 years), while the mean difference was 12.3 years $(0 \cdot 8)$ in the subsample in which social phobia occurred earlier than mood disorder and $7.7(1.1)$ in the subsample 
Table 2. Temporal ordering of age of onset of social phobia and mood disorders among NCS respondents with a history of both disorders

\begin{tabular}{lcccc}
\hline \hline & $\begin{array}{c}\text { Major depression } \\
\%\end{array}$ & $\begin{array}{c}\text { Dysthymia } \\
\%\end{array}$ & $\begin{array}{c}\text { Bipolar disorder } \\
\%\end{array}$ & $\begin{array}{c}\text { Any mood disorder } \\
\%\end{array}$ \\
\hline Social phobia temporally primary* & $71 \cdot 9$ & $76 \cdot 0$ & $47 \cdot 0$ & $68 \cdot 5$ \\
Mood disorder temporally primary* & $18 \cdot 4$ & $17 \cdot 8$ & $40 \cdot 7$ & $21 \cdot 9$ \\
Same-year onset of both disorders & $9 \cdot 7$ & $6 \cdot 1$ & $12 \cdot 3$ & $9 \cdot 6$ \\
\hline \hline
\end{tabular}

* Reported age of onset at least 1 year prior to that of the other disorder.

Table 3. The effects of temporally primary social phobia in predicting first onset of mood disorders

\begin{tabular}{|c|c|c|c|c|c|c|c|c|c|c|c|c|}
\hline & \multicolumn{3}{|c|}{ Major depression } & \multicolumn{3}{|c|}{ Dysthymia } & \multicolumn{3}{|c|}{ Bipolar disorder } & \multicolumn{3}{|c|}{ Any mood disorder } \\
\hline & $\% \dagger$ & OR: & $(95 \% \mathrm{CI})$ & $\% \dagger$ & $\mathrm{OR}+$ & $(95 \% \mathrm{CI})$ & $\% \dagger$ & OR & $(95 \% \mathrm{CI})$ & $\% \dagger$ & OR: & $(95 \% \mathrm{CI})$ \\
\hline \multicolumn{13}{|l|}{ Pure current speaking phobia } \\
\hline Public speaking only & $3 \cdot 2$ & $2 \cdot 1^{*}$ & $(1 \cdot 4-3 \cdot 2)$ & $2 \cdot 2$ & $1 \cdot 5$ & $(0 \cdot 6-3 \cdot 8)$ & $0 \cdot 0$ & - & - & $2 \cdot 7$ & $1 \cdot 7 *$ & $(1 \cdot 1-2 \cdot 7)$ \\
\hline Broader speaking fear & $2 \cdot 5$ & $2 \cdot 5^{*}$ & $(1 \cdot 5-4 \cdot 1)$ & $2 \cdot 1$ & $2 \cdot 3$ & $(0 \cdot 7-7 \cdot 3)$ & $0 \cdot 0$ & - & - & $2 \cdot 4$ & $2 \cdot 4 *$ & $(1 \cdot 5-4 \cdot 1)$ \\
\hline \multicolumn{13}{|l|}{ Other current social phobia } \\
\hline 1 fear & $1 \cdot 0$ & $1 \cdot 6$ & $(0 \cdot 8-3 \cdot 0)$ & $0 \cdot 4$ & $0 \cdot 6$ & $(0 \cdot 1-5 \cdot 9)$ & $4 \cdot 2$ & $5 \cdot 7$ & $(0 \cdot 9-34 \cdot 7)$ & $1 \cdot 0$ & $1 \cdot 6$ & $(0 \cdot 9-2 \cdot 9)$ \\
\hline 2 fears & $3 \cdot 0$ & $2 \cdot 4^{*}$ & $(1 \cdot 5-3 \cdot 9)$ & $4 \cdot 2$ & $3 \cdot 8 *$ & $(1 \cdot 7-8 \cdot 5)$ & $6 \cdot 5$ & $5 \cdot 1$ & $(0 \cdot 8-31 \cdot 4)$ & $2 \cdot 9$ & $2 \cdot 3 *$ & $(1 \cdot 5-3 \cdot 6)$ \\
\hline$\geqslant 3$ fears & $8 \cdot 9$ & $2 \cdot 9 *$ & $(2 \cdot 3-3 \cdot 6)$ & $14 \cdot 1$ & $4 \cdot 5^{*}$ & $(2 \cdot 6-7 \cdot 7)$ & $16 \cdot 0$ & $3 \cdot 3$ & $(0 \cdot 8-13 \cdot 5)$ & $9 \cdot 3$ & $3 \cdot 2 *$ & $(2 \cdot 5-4 \cdot 2)$ \\
\hline Any current social phobia & $18 \cdot 7$ & $2 \cdot 5^{*}$ & $(2 \cdot 0-3 \cdot 1)$ & $23 \cdot 0$ & $3 \cdot 1^{*}$ & $(2 \cdot 2-4 \cdot 4)$ & $26 \cdot 8$ & $2 \cdot 6$ & $(0 \cdot 7-9 \cdot 0)$ & $18 \cdot 4$ & $2 \cdot 5^{*}$ & $(2 \cdot 0-3 \cdot 1)$ \\
\hline PARP\$ & & $10 \cdot 1$ & & & $15 \cdot 5$ & & & $15 \cdot 3$ & & & $9 \cdot 6$ & \\
\hline (S.E.) & & $(1.6)$ & & & $(3 \cdot 1)$ & & & $(13 \cdot 4)$ & & & $(1.6)$ & \\
\hline$\chi_{1}^{2}$ due to any current social phobia & & $60 \cdot 2 *$ & & & $37 \cdot 4^{*}$ & & & $2 \cdot 9$ & & & $62 \cdot 1 *$ & \\
\hline $\begin{array}{l}\chi^{2}{ }_{4} \text { due to current social phobia } \\
\text { subtypes } \|\end{array}$ & & $4 \cdot 9$ & & & $5 \cdot 0$ & & & $2 \cdot 3$ & $\mathrm{df}=2$ & & $15 \cdot 9 *$ & \\
\hline $\begin{array}{l}\chi^{2} \text { due to non-active (remitted) social } \\
\text { phobia }^{+}\end{array}$ & & $12 \cdot 7 *$ & $\mathrm{df}=5$ & & $3 \cdot 3$ & $\mathrm{df}=1$ & & $8 \cdot 5^{*}$ & $\mathrm{df}=1$ & & $6 \cdot 7$ & $\mathrm{df}=5$ \\
\hline
\end{tabular}

* Significant at the 0.05 level.

$\dagger$ The percentage columns report the prevalences of current social phobia in the year of onset of the mood disorder

$\$$ Odds ratios were estimated in discrete-time survival models controlling for prior (to social phobia) history of other NCS/DSM-III-R disorders and sociodemographic variables.

§ PARP (Population Attributable Risk Proportion) was computed by simulation to estimate the expected reduction in the lifetime prevalence of mood disorders if the estimated effects of social phobia were causal and the prevalence of social phobia was reduced to zero. See Kessler et al. (1997) for a more complete discussion of estimation procedures.

- Significance test with one degree of freedom for the effect of any current social phobia in predicting subsequent onset of mood disorder.

$\|$ Incremental significance test with four degrees of freedom for the effects of current social phobia subtypes $v$. any social phobia in predicting subsequent onset of mood disorder.

+ Significance test for the effects of remitted social phobia in predicting subsequent onset of major depression $(\mathrm{df}=5)$, dysthymia $(\mathrm{df}=1)$, bipolar disorder $(\mathrm{df}=1)$, any mood disorder $(\mathrm{df}=5)$.

where mood disorder occurred earlier than social phobia. As in Table 1, the pattern is different for mania than the other mood disorders. The proportion of co-morbid cases that reported temporal priority of social phobia before mania $(47.0 \%)$ is not meaningfully higher than the proportion that reported mania before social phobia $(40.7 \%)$. The situation is different for major depression and dysthymia, where the proportions reporting temporally primary social phobia $(71.9 \%$ and $76.0 \%$, respectively) are dramatically higher than the proportions reporting primary mood disorders $(9.7 \%$ and $6.1 \%$, respectively).

The $9.6 \%$ of same-year onsets is nearly six times as high as one would expect on the basis of chance alone. There are a number of plausible interpretations of this finding, two of which can be examined in the NCS data. One is that it is due to bias in the recollection of onset ages as being the same when they actually differed. In order to test this hypothesis, we focused on 
respondents who reported a first onset of mood disorder at a particular age and an onset of social phobia either before this age or at the same age as the onset of the mood disorder. If recall bias was at work, we would expect that the proportion of respondents who recalled sameyear onsets would increase as age at interview increases (i.e. length of recall period) controlling for age of onset of mood disorder. No such effect was found (results not shown). A second possibility is that same-year onsets are due to traumatic life events that precipitate both social phobia and mood disorder. In order to test this hypothesis, we compared reported ages of onset of social phobia and mood disorders with reports from other sections of the NCS about the lifetime occurrence and ages of exposure to traumatic life events. We found that $36.0 \%$ of respondents with same-year onsets of social phobia and mood disorder reported a traumatic life event in this year compared to $8.0 \%$ of respondents who reported different years of onset of social phobia and mood disorder.

\section{The effects of social phobia on the onset of mood disorders}

As noted above, discrete-time survival analysis with person-year as the unit of analysis was used to study the time-lagged effects of temporally primary social phobia in predicting the subsequent first onset of mood disorders. The models controlled for prior (to social phobia) history of other NCS/DSM-III-R disorders as well as for basic sociodemographics (age, cohort, sex, race-ethnicity). Results are shown in Table 3. Current social phobia significantly predicts mood disorders overall $\left(\chi^{2}{ }_{1}=62 \cdot 1, P<0 \cdot 001\right)$ as well a major depression $\left(\chi^{2}{ }_{1}=60 \cdot 2, P<\right.$ $0 \cdot 001)$ and dysthymia $\left(\chi^{2}{ }_{1}=37 \cdot 4, P<0 \cdot 001\right)$, with ORs ranging between $2 \cdot 5$ and $3 \cdot 1$ across these different outcomes. There is no significant effect on bipolar disorder $\left(\chi^{2}{ }_{1}=2 \cdot 9, P=0 \cdot 089\right)$ due to the small number of bipolars in the study, but the 2.6 OR linking primary social to the subsequent onset of bipolar disorder is nonetheless in the range found for the other mood disorders. (The OR for any mood disorder $\left(\chi^{2}{ }_{4}\right.$ $=15.9, P<0.001)$, but not for any of the three types of mood disorder, varies as a function of number and type of social fears, with the strongest $\mathrm{OR}$ found among social phobics having three or more social fears $(3 \cdot 2)$ and the lowest among social phobics with only one far (1.6-1.7).) Population attributable risk proportions of mood disorders associated with prior social phobia range between $9.6 \%$ and $15.5 \%$ across outcomes.

More detailed analyses investigated three potentially important elaborations of these results. First, the effects of non-active remitted social phobia were found to be much less powerful than those of active ongoing social phobia. Remitted social phobia has no significant effect in predicting first onset of either mood disorders $\left(\chi^{2}{ }_{5}=6 \cdot 7, \quad P=0 \cdot 244\right)$ or dysthymia $\left(\chi_{5}^{2}=3 \cdot 3, \quad P=0.653\right)$ and substantively modest effects in predicting major depression $\left(\chi^{2}{ }_{5}=12 \cdot 7, P=0.026\right)$ and bipolar disorder $\left(\chi^{2}{ }_{1}=8 \cdot 5, P=0.003\right)$. Secondly, as shown in Table 4, the effects of persistent social phobia do not vary significantly with time since first onset other than for same-year onsets. The number of NCS respondents with bipolar disorder was too small to carry out this analysis, but the results for major depression, dysthymia, and any mood disorder are consistent in showing that the ORs do not become larger as the duration of social phobia increases. Thirdly, we found no evidence that the effects of social phobia vary by cohort or by age of onset of the mood disorder. However, there was a significantly $\left(\chi^{2}{ }_{1}=7 \cdot 9, P=0 \cdot 005\right)$ more powerful OR of social phobia in predicting subsequent earlyonset (defined as onset prior to age 25) dysthymia $(\mathrm{OR}=4 \cdot 4,95 \% \mathrm{CI}=2 \cdot 9-6 \cdot 7)$ than later-onset dysthymia $(\mathrm{OR}=1 \cdot 9,95 \% \mathrm{CI}=1 \cdot 1-3 \cdot 2)$.

\section{The effects of social phobia on major depression symptom profiles}

Previous analysis of depressive symptoms in the NCS found a clear distinction between respondents with a typical vegetative symptom profile and those with a more atypical reverse vegetative symptom profile (Sullivan et al. 1998). Based on previous evidence that social phobia might be associated with atypical depression (Alpert et al. 1997), we estimated a model to determine whether prior history of social phobia or particular social phobia subtypes discriminates depression with a typical versus atypical symptom profile. No such evidence was found (results not shown). 
Table 4. The effects of duration of temporally primary active/current social phobia in predicting first onset of mood disorder †

\begin{tabular}{|c|c|c|c|c|c|c|c|c|c|}
\hline \multirow{2}{*}{$\begin{array}{l}\text { Duration (in years) since } \\
\text { first onset of social phobia }\end{array}$} & \multicolumn{3}{|c|}{ Major depression } & \multicolumn{3}{|c|}{ Dysthymia } & \multicolumn{3}{|c|}{ Any mood disorder } \\
\hline & $\% \ddagger$ & OR & $(95 \% \mathrm{CI})$ & $\%$ & OR & $(95 \% \mathrm{CI})$ & $\% 末$ & OR & $(95 \% \mathrm{CI})$ \\
\hline 0 & $2 \cdot 5$ & $6 \cdot 0 *$ & $(3 \cdot 6-9 \cdot 8)$ & 1.9 & $5 \cdot 2 *$ & $(2 \cdot 1-13 \cdot 1)$ & $2 \cdot 5$ & $5 \cdot 9 *$ & $(3 \cdot 6-9 \cdot 7)$ \\
\hline $1-3$ & $3 \cdot 1$ & $2 \cdot 9 *$ & $(1 \cdot 9-4 \cdot 5)$ & $1 \cdot 5$ & $1 \cdot 6$ & $(0 \cdot 3-7 \cdot 1)$ & $2 \cdot 8$ & $2 \cdot 5^{*}$ & $(1 \cdot 7-3 \cdot 8)$ \\
\hline $4-6$ & $2 \cdot 5$ & $2 \cdot 3 *$ & $(1 \cdot 4-3 \cdot 7)$ & $4 \cdot 1$ & $4 \cdot 1^{*}$ & $(1 \cdot 9-8 \cdot 8)$ & $2 \cdot 8$ & $2 \cdot 5^{*}$ & $(1 \cdot 7-3 \cdot 8)$ \\
\hline $7-9$ & $2 \cdot 5$ & $2 \cdot 4^{*}$ & $(1 \cdot 5-3.9)$ & $3 \cdot 4$ & $3 \cdot 8 *$ & $(1 \cdot 8-7 \cdot 8)$ & $2 \cdot 3$ & $2 \cdot 3^{*}$ & $(1 \cdot 5-3 \cdot 5)$ \\
\hline$\geqslant 10$ & $8 \cdot 1$ & $2 \cdot 1 *$ & $(1 \cdot 6-2 \cdot 7)$ & $12 \cdot 1$ & $2 \cdot 9^{*}$ & $(1 \cdot 6-2 \cdot 7)$ & $8 \cdot 0$ & $2 \cdot 2 *$ & $(1 \cdot 6-2 \cdot 9)$ \\
\hline
\end{tabular}

* Significant at the 0.05 level.

$\dagger$ Odds ratios were estimated in discrete-time survival models controlling for prior (to social phobia) history of other NCS/DSM-III-R disorders and sociodemographic variables.

\$ The percentage columns report the prevalences of social phobia duration in the year of onset of the mood disorder.

Table 5. The effects of temporally primary social phobia in predicting the severity of secondary major depressiont

\begin{tabular}{|c|c|c|c|c|c|c|c|c|c|c|c|c|c|c|c|c|}
\hline & \multicolumn{6}{|c|}{ Pure speaking phobia } & \multirow{2}{*}{\multicolumn{6}{|c|}{ Other social phobia }} & & & & \\
\hline & \multirow{2}{*}{\multicolumn{3}{|c|}{$\begin{array}{c}\text { Public speaking } \\
\text { only }\end{array}$}} & \multirow{2}{*}{\multicolumn{3}{|c|}{$\begin{array}{c}\text { Broader speaking } \\
\text { fears }\end{array}$}} & & & & & & & & & & \\
\hline & & & & & & & \multicolumn{3}{|c|}{1 or 2 fears } & \multicolumn{3}{|c|}{3 or more fears } & \multicolumn{3}{|c|}{ Any social phobia } & \multirow[b]{2}{*}{$x^{2}+$} \\
\hline & $\% \S$ & OR & $(95 \% \mathrm{CI})$ & $\% \S$ & OR & $(95 \% \mathrm{CI})$ & $\% \S$ & OR & $(95 \% \mathrm{CI})$ & $\% \S$ & OR & $(95 \% \mathrm{CI})$ & $\% \S$ & OR & $(95 \% \mathrm{CI})$ & \\
\hline Attempt suicide & $1 \cdot 5$ & $0 \cdot 3$ & $(0 \cdot 1-1 \cdot 0)$ & $1 \cdot 3$ & $0 \cdot 3$ & $(0 \cdot 0-1 \cdot 5)$ & $4 \cdot 5$ & $1 \cdot 0$ & $(0 \cdot 3-3 \cdot 0)$ & $15 \cdot 3$ & $1 \cdot 7$ & $(0 \cdot 9-3 \cdot 2)$ & $22 \cdot 5$ & $1 \cdot 0$ & $(0 \cdot 6-1 \cdot 7)$ & $6 \cdot 5$ \\
\hline See any prof. & $3 \cdot 3$ & $1 \cdot 0$ & $(0 \cdot 4-2 \cdot 3)$ & $2 \cdot 4$ & $0 \cdot 9$ & $(0 \cdot 2-3 \cdot 2)$ & $5 \cdot 3$ & $2 \cdot 3 *$ & $(1 \cdot 0-5 \cdot 0)$ & $10 \cdot 8$ & $1 \cdot 7$ & $(0 \cdot 9-3 \cdot 1)$ & $21 \cdot 9$ & $1 \cdot 5$ & $(1 \cdot 0-2 \cdot 3)$ & $7 \cdot 3$ \\
\hline Interfere a lot & $1 \cdot 8$ & $0 \cdot 4 *$ & $(0 \cdot 2-0 \cdot 8)$ & $2 \cdot 2$ & $0 \cdot 7$ & $(0 \cdot 2-2 \cdot 3)$ & $5 \cdot 0$ & $1 \cdot 3$ & $(0 \cdot 5-3 \cdot 1)$ & $12 \cdot 8$ & $1.9 *$ & $(1 \cdot 0-3 \cdot 5)$ & $21 \cdot 8$ & $1 \cdot 2$ & $(0 \cdot 7-2 \cdot 0)$ & $12 \cdot 8^{*}$ \\
\hline Impaired work & $3 \cdot 5$ & $1 \cdot 2$ & $(0 \cdot 4-3 \cdot 4)$ & $2 \cdot 5$ & $0 \cdot 7$ & $(0 \cdot 2-3 \cdot 0)$ & $5 \cdot 4$ & 1.9 & $(0 \cdot 8-4 \cdot 7)$ & $11 \cdot 6$ & $2 \cdot 1$ & $(1 \cdot 1-2 \cdot 9)$ & $23 \cdot 1$ & 1.6 & $(0 \cdot 9-2 \cdot 8)$ & $8 \cdot 7$ \\
\hline Was hospitalized & $7 \cdot 7$ & $3 \cdot 0$ & $(1 \cdot 0-9 \cdot 3)$ & $1 \cdot 3$ & $0 \cdot 4$ & $(0 \cdot 1-2 \cdot 0)$ & $4 \cdot 6$ & $1 \cdot 2$ & $(0 \cdot 3-4 \cdot 7)$ & $17 \cdot 5$ & 1.9 & $(0 \cdot 9-4 \cdot 3)$ & $31 \cdot 1$ & $1 \cdot 6$ & $(0 \cdot 8-3 \cdot 2)$ & $8 \cdot 8$ \\
\hline \multirow[t]{2}{*}{ Any impairment } & $3 \cdot 2$ & $0 \cdot 9$ & $(0 \cdot 3-2 \cdot 6)$ & $2 \cdot 6$ & $0 \cdot 8$ & $(0 \cdot 1-4 \cdot 9)$ & $5 \cdot 1$ & $2 \cdot 0$ & $(0 \cdot 8-5 \cdot 2)$ & $11 \cdot 8$ & $3 \cdot 2 *$ & $(1 \cdot 6-6 \cdot 1)$ & $22 \cdot 7$ & $1.8^{*}$ & $(1 \cdot 1-3 \cdot 0)$ & $16 \cdot 0^{*}$ \\
\hline & - & $0 \cdot 8$ & $(0 \cdot 5-1 \cdot 4)$ & - & 0.6 & $(0 \cdot 3-1 \cdot 2)$ & - & $1 \cdot 4$ & $(0 \cdot 9-2 \cdot 1)$ & - & 1.8 & $(1 \cdot 2-2 \cdot 6)$ & - & $1 \cdot 3$ & $(0 \cdot 9-1 \cdot 8)$ & $17 \cdot 2 *$ \\
\hline
\end{tabular}

* Significant at 0.05 level.

$\dagger$ Odds ratios were estimated in logistic regression models controlling for prior (to social phobia) history of other NCS/DSM-III-R disorders, sociodemographics, age of onset of mood disorder, and number of years since onset of mood disorder.

$\$ \chi^{2}$ tests evaluate the significance of the set of predictors associated with social phobia subtypes.

$\S$ The percentage columns report the prevalences of each severity indicator among respondents with a history of social phobia.

Table 6. The effects of prior social phobia in predicting the course of secondary major depression†

\begin{tabular}{|c|c|c|c|c|c|c|c|c|c|c|c|c|c|}
\hline & \multicolumn{4}{|c|}{ Pure speaking phobia } & \multirow{2}{*}{\multicolumn{5}{|c|}{ Other social phobia }} & \multirow{3}{*}{\multicolumn{3}{|c|}{ Any social phobia }} & \multirow[b]{4}{*}{$x^{2}$} \\
\hline & \multirow{2}{*}{\multicolumn{2}{|c|}{$\begin{array}{l}\text { Public speaking } \\
\text { only }\end{array}$}} & \multirow{2}{*}{\multicolumn{2}{|c|}{$\begin{array}{l}\text { Broader speaking } \\
\text { fears }\end{array}$}} & & & & & & & & & \\
\hline & & & & & \multicolumn{2}{|c|}{1 or 2 fears } & \multicolumn{3}{|c|}{3 or more fears } & & & & \\
\hline & $\% \S \mathrm{OR}$ & $(95 \% \mathrm{CI})$ & $\% \S \mathrm{OR}$ & $(95 \% \mathrm{CI})$ & $\% \S \mathrm{O}$ & $\mathrm{R}(95 \% \mathrm{CI})$ & $\% \S$ & OR & $(95 \% \mathrm{CI})$ & $\% \S$ & OR & $(95 \% \mathrm{CI})$ & \\
\hline$\geqslant 10$ lifetime episodes & $3 \cdot 6 \quad 1 \cdot 3$ & $(0 \cdot 3-6 \cdot 3)$ & $1.0 \quad 0.2$ & $(0 \cdot 0-2 \cdot 5)$ & $5 \cdot 61$ & $4 \quad(0 \cdot 6-3 \cdot 3)$ & $17 \cdot 4$ & $42.7 *$ & $(1 \cdot 2-6 \cdot 1)$ & 27.6 & $1.7 *$ & $(0 \cdot 9-3 \cdot 2)$ & $10 \cdot 1^{*}$ \\
\hline Chronic episode $(\geqslant 2$ years $)$ & $2 \cdot 9 \quad 0.8$ & $(0 \cdot 3-2 \cdot 5)$ & $1.8 \quad 0.6$ & $(0 \cdot 2-1 \cdot 9)$ & $2 \cdot 00$ & $4 \quad(0 \cdot 1-1 \cdot 2)$ & $11 \cdot 7$ & $7 \quad 1 \cdot 3$ & $(0 \cdot 6-2 \cdot 9)$ & $18 \cdot 4$ & 0.9 & $(0 \cdot 5-1 \cdot 6)$ & $4 \cdot 2$ \\
\hline Depression in past 30 days & $4.9 \quad 1.9$ & $(0 \cdot 6-6 \cdot 2)$ & $1 \cdot 2 \quad 0 \cdot 4$ & $(0 \cdot 1-1 \cdot 6)$ & 5.91 & $5 \quad(0 \cdot 6-4 \cdot 0)$ & $16 \cdot 0$ & $2 \cdot 5^{*}$ & $(1 \cdot 4-4 \cdot 4)$ & $28 \cdot 0$ & $1.7^{*}$ & $(1 \cdot 0-2 \cdot 9)$ & $11 \cdot 7 *$ \\
\hline
\end{tabular}

* Significant at 0.05 level.

$\uparrow$ Odds ratios were estimated in logistic regression models controlling for prior (to social phobia) history of other NCS/DSM-III-R disorders, sociodemographics, age of onset of mood disorder and number of years since onset of mood disorder.

$\ddagger \chi^{2}$ tests evaluate the significance of the set of predictors associated with social phobia subtypes.

$\S$ The percentage columns report the prevalences of each course indicator among respondents with a history of social phobia. 


\section{The effects of social phobia on the severity of major depression}

The results in Table 5 show the effects of temporally primary social phobia in predicting severity indicators of major depression. As in Tables 3 and 4, the models controlled for prior (to social phobia) history of other NCS/DSMIII-R disorders as well as for sociodemographics. We also controlled for age of onset of depression and number of years between onset and the time of interview. Parallel analyses of social phobics with co-morbid dysthymia or mania could not be carried out due to small sample sizes. The table documents a generally positive pattern of associations between overall social phobia and seeing a professional for depression, interference with life activities due to the depression, work impairment due to the depression, being hospitalized for depression and reporting at least one of these severity indicators. However, the significant 1.8 OR between any social phobia and any depression impairment is due entirely to respondent with $1-2(\mathrm{OR}=2 \cdot 0)$ or $\geqslant 3(\mathrm{OR}=$ $3 \cdot 2)$ social fears. There is no consistent evidence for any elevated depression severity indication associated with social phobic having only one fear. Neither is social phobia of any sort associated with elevated risk of suicide attempts during depressive episodes.

\section{The effects of social phobia on the course of major depression}

The results in Table 6 show the effects of temporally primary social phobia in predicting several indicators of the course of major depression. The same controls as those in Table 5 were included in these models. Social phobia with $\geqslant 3$ social fears is found to be associated with significantly elevated odds of having a large number $(\geqslant 10)$ of depressive episodes (OR = $2 \cdot 7$ ) and of current depression (2.5), but not with a history of chronic depression (defined as an episode lasting 2 years or longer). Pure speaking social phobia and social phobia with only 1-2 non-speaking fears are not associated with any of these indicators of course. Parallel analyses of social phobics with co-morbid dysthymia or mania could not be carried out due to small sample sizes.

\section{DISCUSSION Limitations}

Five limitations of the above results have to be noted. First, the NCS is a cross-sectional survey, which means that inferences about temporal ordering are based on retrospective reports. As noted in the methods section, we attempted to improve accuracy of age of onset reporting. However, errors doubtlessly remain that would have been reduced either if we had used a life chart scheme to anchor retrospective reports (e.g. Lyketsos et al. 1994; Hunt \& Andrews, 1995) or if we had used longitudinal data. Secondly, the CIDI is a lay-administered diagnostic interview that only imperfectly captures the diagnostic distinctions made by experienced clinicians. The evidence of good consistency of the CIDI with independent clinical diagnoses argues against a pervasive bias, but it remains possible that CIDI imprecision affects results. Thirdly, the CIDI focuses largely on lifetime disorders. As a result, we have been concerned here with temporal ordering of first onsets and have said nothing about the order of onset of social phobia and mood disorders in particular episodes. There is no reason to think that temporal priority in first onset will tell us much about temporal priority in episodes. Fourthly, the results reported here apply mostly to the roughly two-thirds of co-morbid social phobias with mood disorder whose mood disorder occurred subsequent to the onset of their social phobia. Fifthly, as parallel analyses were not carried out for other anxiety disorders, there is no information in this report to suggest that the effects on mood disorder are specific to social phobia. It might well be that other anxiety disorders have similar or greater effects. As we controlled for all other NCS/DSM-III-R disorders in the analyses, though, the results reported here are not due to those other disorders.

\section{Consistency with previous research}

Within the context of these limitations, the basic results found here are very similar to those of previous research in documenting strong lifetime co-morbidities between social phobia and mood disorders. However, our finding in Table 1 that 
lifetime co-morbidity is stronger for bipolar than unipolar depression is inconsistent with at least one cross-sectional clinical study that found social phobia to be relate to unipolar, but not bipolar, depression (Pini et al. 1997). This inconsistency might be related to the fact that, as shown in Table 2 , social phobia is much more likely to occur after bipolar depression than other mood disorders. This means that it might require long-term follow-up of clinical samples of bipolars to detect the strong association with social phobia documented in Table 2. The reason for this difference between bipolar and nonbipolar depression is unclear. No efforts were made to investigate reasons for the difference due to the small number of bipolars $(N=32)$ and very small number of bipolars with comorbid social phobia $(N=15)$ in the NCS.

Our results are similar to those of previous studies (Merikangas et al. 1996; Parker et al. 1997) in finding a clear temporal priority of social phobia before non-bipolar mood disorders. Our results are also consistent with others (Merikangas \& Angst, 1995; Alpert et al. 1997) in finding significant associations of temporally primary social phobia with the subsequent onset, severity and course of depressive disorders. Unfortunately, most of our analyses of these outcomes were restricted to non-bipolar mood disorders due to the small number of confirmed bipolars in the NCS. We found some variation in the effects in predicting severity, although this variation might be due to chance in such a large number of replications. We also found some variation with regard to course. Specifically, while primary social phobia is significantly associated with having a large number of depressive episodes, it is unrelated to whether any of these episodes persists long enough (2 years or more) to be classified as chronic. Again, though, this variation might be due to chance. It is consequently important that these results be replicated in independent epidemiological datasets. We failed to replicate the finding of one previous study that social phobia is more strongly related to early-onset than later-onset depression (Parker et al. 1997) and the finding of another study that social phobia is more strongly associated with atypical than typical symptoms of depression (Alpert et al. 1997).

Several potentially important specifications are notable. The first is that the relationships of primary social phobia with onset, severity, and course of any mood disorder vary with number of social fears. Pure public speaking social phobia and social phobia associated with only one other social fear are the least powerful predictors of onset and are not significantly related to severity or course of mood disorders. Social phobia with three or more non-exclusive speaking fears is the most powerful and consistent predictor of these various outcomes. These results are consistent with the findings of previous studies that only generalized social phobia substantially interferes with role functioning and quality of life (Kessler et al. 1998b; Wittchen et al. 1998). However, it is important to recognize, in considering the results regarding social phobia subtypes in the NCS, that we cannot clearly distinguish DSM-III-R generalized social phobia due to the fact that the CIDI does not include questions about interactional fears or a large enough set of questions about overall social fears to operationalize the DSM requirement for the generalized subtype that respondents must have excessive fears of 'most' social situations. It is conceivable, then, that more detailed assessment in future surveys will show that the effects of social phobia are confined to the even smaller subset of cases with generalized social phobia.

Another noteworthy specification involves the association between duration of primary social phobia and onset of subsequent mood disorder. Consistent with previous NCS analyses that have documented strong same-year associations between first onset of mood disorders and first onset of other co-morbid conditions (Kessler et al. 1996), we found that mood disorders have their highest conditional odds of onset in the year of onset of social phobia. It is not clear why this is the case. Nor does it mean that the sameyear onsets are coincident. It might be that social phobia typically has an onset earlier than mood disorder within the same year. One otherwise plausible possibility, that the strong same-year association is due to recall bias, is inconsistent with results reported above that length of the recall period is unrelated to probability of reporting same-year onset. A second possibility is that some acute traumatic life experience triggered onsets of both disorders in some cases of this sort. This is consistent with 
our finding that a high proportion of NCS respondents with PTSD report the onset of diverse anxiety and mood disorders as occurring in the same year as the onset of their PTSD (Kessler et al. 1995b). It is also consistent with the finding that $30.0 \%$ of respondents with same-year onsets reported a traumatic life event in this year elsewhere in the NCS compared to $8.0 \%$ of respondents who reported different years of onset of social phobia and mood disorder. Another possibility is that the sameyear clustering of social phobia and mood disorder onsets represents diagnostic confusion between social phobia and depression with rejection sensitivity (Katschnig, 1996). We have no way of evaluating this possibility in the NCS, but it is an issue that is worthy of investigation in future epidemiological studies.

Aside from this strong same-year clustering, we failed to find evidence of a change in the association between primary social phobia and subsequent mood disorders as a function of the duration of the phobia. This is an important finding from the perspective of secondary mood disorder because it means that elevated risk of such disorders persists for many years after the onset of social phobia. This finding is at least superficially inconsistent with the widely proposed, but previously untested, hypothesis that secondary depression often occurs as an exhaustion response to persistent anxiety (Akiskal, 1990). It should be noted, though, that this proposed mechanism might be more plausible in accounting for the effects on mood disorders of more extreme forms of anxiety as are often seen in patients with panic disorder or obsessive-compulsive disorder or that the effect might exist over a shorter lag period than the fairly coarse time intervals we were required to use in the NCS in order to have adequate statistical power to plot time trends.

Finally, we found that active social phobia is a more powerful predictor of depressive disorders than history of remitted social phobia. It is important to note that this specification is not found in all analyses of co-morbidity. For example, a parallel NCS investigation of panic and depression found that remitted panic is as important as active panic in predicting the subsequent onset of mood disorders (Kessler et al. 1999). The fact that this is not the case for social phobia - that risk of mood disorders is substantially reduced when the social phobia remits - raises the possibility that successful treatment of social phobia might represent a practical opportunity for the primary prevention of secondary mood disorders (Kessler \& Price, 1993). A potentially feasible way to evaluate this possibility would be to carry out a long-term comparative follow-up evaluation of pure social phobics who participated either in the experimental or control arms of treatment trials for social phobia to evaluate whether those in treatment had a reduced risk of subsequent mood disorders than those in the control arm.

\section{Implications}

Previous NCS analyses have documented that social phobia is a commonly occurring and seriously impairing disorder that usually has an early age of onset and is often associated with high risk of chronicity and secondary comorbidity (Kessler et al. 1998b). Another important result from previous NCS analyses is that social phobics seldom seek professional treatment unless they also suffer from some other co-morbid disorder (Kessler et al. 1999). This combination of high prevalence, early onset, chronicity, impairment, risk of secondary co-morbidity, and low probability of treatment makes social phobia an important disorder from a public health perspective. Yet, as noted in the introduction, many people are unaware of the importance of social phobia. This is presumably due to the fact that social phobia is under diagnosed (Liebowitz et al. 1985; Weiller et al. 1996; Fones et al. 1998) and incorrectly regarded as not seriously impairing (Hirschfeld, 1995; Judd, 1994; Wittchen \& Beloch, 1996).

Early outreach and intervention with social phobics prior to the onset of co-morbid disorders is an appealing strategy in that it would reduce treatment complexity. Our analysis of time lags suggests that the typical primary social phobic suffers for more than a decade before the onset of secondary mood disorder, providing a very wide window of opportunity for intervention. Intervention during this period might also prevent subsequent mood disorders. Treatment of social phobics with numerous fears appears to be of primary importance here both because this generalized subtype is the most impaired (Kessler et al. 1998b) and because it is most strongly related to subsequent onset and severity 
of mood disorders. Given our prediction that roughly $10 \%$ of mood disorders might be prevented by successful early intervention with social phobia and the finding that socially phobic depressives have twice as many impairments and two-thirds more episodes as depressives without social phobia, such focused interventions with generalized social phobics could well reduce the point prevalence of seriously impairing mood disorders by as much as one-fourth. This substantial potential secondary effect, when combined with the realization that generalized social phobia is highly impairing in its own right, argues strongly for future consideration of this disorder as a public health intervention target.

The US National Comorbidity Survey (NCS) is a collaborative epidemiological investigation of the prevalence, causes and consequences of psychiatric morbidity and co-morbidity in the United States, supported by the National Institute of Mental Health (R01 MH46376, R01 MH49098 and R01 MH52861) with supplemental support from the National Institute of Drug Abuse (through a supplement to MH46376) and the W. T. Grant Foundation (90135190), to Ronald C. Kessler, Principal Investigator. Preparation for this report was also supported by a Research Scientist Award to Kessler (K05 MH00507) and an unrestricted educational grant from SmithKline Beecham. Collaborating NCS sites and investigators are: The Addiction Research Foundation (Robin Room), Duke University Medical Center (Dan Blazer, Marvin Swartz), Harvard Medical School (Richard Frank, Ronald Kessler), Johns Hopkins University (James Anthony, William Eaton, Philip Leaf), the Max Planck Institute of Psychiatry (Hans-Ulrich Wittchen), the Medical College of Virginia (Kenneth Kendler), the University of Miami (R. Jay Turner), the University of Michigan (Lloyd Johnson, Roderick Little), New York University (Patrick Shrout), SUNY Stony Brook (Evelyn Bromet) and Washington University School of Medicine (Linda Cottler, Andrew Heath).

A complete list of all NCS publications along with abstracts, study documentation, interview schedules and the raw NCS public-use data files can be obtained directly from the NCS Homepage by using the URL: http://www.hcp.med.harvard.edu/ncs.

\section{REFERENCES}

Akiskal, H. S. (1990). Toward a clinical understanding of the relationship of anxiety and depressive disorders. In Comorbidity of Mood and Anxiety Disorders (ed. J. D. Maser and C. R. Cloninger), pp. 597-607. American Psychiatric Press: Washington, DC.
Alpert, J. E., Maddocks, A., Rosenbaum, J. F. \& Fava, M. (1994). Childhood psychopathology retrospectively assessed among adults with early onset major depression. Journal of Affective Disorders 31, 165-171.

Alpert, J. E., Uebelacker, L. A., McLean, N. E., Nierenberg, A. A., Pava, J. A., Worthington, J. J. III, Tedlow, J. R., Rosenbaum, J. F. \& Fava, M. (1997). Social phobia, avoidant personality disorder and atypical depression: co-occurrence and clinical implications. Psychological Medicine 27, 627-633.

Angst, J. (1996). Comorbidity of mood disorders: a longitudinal prospective study. British Journal of Psychiatry 168, 31-37.

American Psychiatric Association (1987). Diagnostic and Statistical Manual of Mental Disorders, 3rd edn. Revised. (DSM-III-R.) Psychiatric Association: Washington, DC.

Brawman-Mintzer, O., Lydiard, R. B., Emmanuel, N., Payeur, R., Johnson, M., Roberts, J., Jarrell, M. P. \& Ballenger, J. C. (1993). Psychiatric comorbidity in patients with generalized anxiety disorder. American Journal of Psychiatry 150, 1216-1218.

Efron, B. (1988). Logistic regression, survival analysis, and the Kaplan-Meier Curve. Journal of the American Sociological Association 83, 414-425.

Fones, C. S., Manfro, G. C. \& Pollack, M. H. (1998). Social phobia: an update. Harvard Review of Psychiatry 5, 247-59.

Hecht, H., von Zerssen, D., Krieg, C., Possl, J. \& Wittchen, H.-U. (1989). Anxiety and depression: comorbidity, psychopathology, and social functioning. Comprehensive Psychiatry 30, 420-433.

Hirschfeld, R. M. (1995). The impact of health care reform on social phobia. Journal of Clinical Psychiatry 5, 13-17.

Hunt, C. \& Andrews, G. (1995). Comorbidity in the anxiety disorders: the use of a life-chart approach. Journal of Psychiatric Research 29, 467-480.

Judd, L. L. (1994). Social phobia: a clinical overview. Journal of Clinical Psychiatry 55 (Suppl.) 5-9.

Katsching, H. (1996). The boundaries of social phobia and its subtypes: workshop report 1. International Clinical Psychopharmacology 3, 101-102.

Kendler, K. S., Gallagher, T. J., Abelson, J. M. \& Kessler, R. C. (1996). Lifetime prevalence, demographic risk factors, and diagnostic validity of nonaffective psychosis as assessed in a US community sample: the National Comorbidity Survey. Archives of General Psychiatry 53, 1022-1031.

Kessler, R. C. (1995). Epidemiology of psychiatric comorbidity. In Textbook in Psychiatric Epidemiology (ed. M. T. Tsuang, M. Tohan and G. E. P. Zahner), pp. 179-197. John Wiley and Sons: New York.

Kessler, R. C. (1997). The prevalence of psychiatric comorbidity. In Treatment Strategies for Patients with Psychiatric Comordities (ed. S. Wetzler and W. C. Sanderson), pp. 23-48. John Wiley \& Sons: New York.

Kessler, R. C. (1999). Some considerations in making resource allocation decisions for the treatment of psychiatric disorders. In Unmet Need in Mental Health Service Delivery (ed. G. Andrews). Cambridge University Press: Cambridge. (In the press.)

Kessler, R. C. \& Price, R. H. (1993). Primary prevention of secondary disorders: a proposal and agenda. American Journal of Community Psychology 21, 607-633.

Kessler, R. C., McGonagle, K. A., Zhao, S., Nelson, C. B., Hughes, M., Eshleman, S., Wittchen, H.-U. \& Kendler, K. S. (1994). Lifetime and 12-month prevalence of DSM-III-R psychiatric disorders in the United States: results from the National Comorbidity Survey. Archives of General Psychiatry 51, 8-19.

Kessler, R. C., Little, R. J. A. \& Groves, R. M. (1995a). Advances in strategies for minimizing and adjusting for survey nonresponse. Epidemiological Reviews 17, 192-204.

Kessler, R. C., Sonnega, A., Bromet, E., Hughes, M. \& Nelson, C. B. $(1995 b)$. Posttraumatic stress disorder in the National Comorbidity Survey. Archives of General Psychiatry 52, 1048-1060. Kessler, R. C., Nelson, C. B., McGonagle, K. A., Lui, J., Swartz, M. S. \& Blazer, D. C. (1996). Comorbidity of DSM-III-R Major 
depressive disorder in the general population: results from the US National Comorbidity Survey. British Journal of Psychiatry 168, 17-30.

Kessler, R. C., Rubinow, D. R., Holmes, C., Abelson, J. M. \& Zhao, S. (1997). The epidemiology of DSM-III-R bipolar I disorder in a general population survey. Psychological Medicine 27, 1079-1089.

Kessler, R. C., Stang, P., Wittchen, H.-U., Ustun, B., Roy-Byrne, P. P. \& Walters, E. E. (1998a). Lifetime panic-depression comorbidity in the National Comorbidity Survey. Archives of General Psychiatry 55, 801-808.

Kessler, R. C., Stein, M. B. \& Berglund, P. A. (1998b). Social phobia subtypes in the National Comorbidity Survey. American Journal of Psychiatry 155, 613-619.

Kessler, R. C., Wittchen, H.-U., Abelson, J. M., McGonagle, K. A., Schwarz, N., Kendler, K. S., Knauper, B. \& Zhao, S. (1998c). Methodological studies of the Composite International Diagnosis Interview (CIDI) in the US National Comorbidity Survey. International Journal of Methods in Psychiatric Research 7, 33-55.

Kessler, R. C., Zhao, S., Kats, S. J., Kouzis, A. C., Frank, R. G., Edlund, M. \& Leaf, P. (1999). Past year of outpatient services for psychiatric problems in the National Comorbidity Survey. American Journal of Psychiatry 156: 115-123.

Kish, L. \& Frankel, M. R. (1974). Inferences from complex samples. Journal of the Royal Statistical Society (series B) 36, 1-37.

Knauper, B., Cannell, C. F., Schwarz, N., Bruce, M. L. \& Kessler, R. C. (1999). Improving accuracy of major depression age of onset reports in the US National Comorbidity Survey. International Journal of Methods in Psychiatric Research (in the press).

Kraemer, C. K., Kazdin, A. E., Offord, D. R., Kessler, R. C., Jensen, P. S. \& Kupfer, D. J. (1997). Coming to terms with the terms of risk. Archives of General Psychiatry 54, 337-343.

Lecrubier, Y. \& Weiller, E. (1997). Comorbidities in social phobia. International Clinical Psychopharmacology 12 (suppl. 6), S17-21.

Liebowitz, M. R., Gorman, J. M., Fyer, A. J. \& Klein, D. F. (1985). Social phobia: review of a neglected anxiety disorder. Archives of General Psychiatry 42, 729-736.

Lyketsos, C. G., Nestadt, G., Cwi, J., Heithoff, K. \& Eaton, W. W. (1994). The Life-Chart Interview: a standardized method to describe the course of psychopathology. International Journal of Methods in Psychiatric Research 4, 143-155.

Maser, J. D. \& Cloninger, C. R. (1990). Comorbidity of Mood and Anxiety Disorders. American Psychiatric Press: Washington, DC.

Merikangas, K. R. \& Angst, J. (1995). Comorbidity and social phobia: evidence from clinical, epidemiologic and genetic studies. Archives of Psychiatry and Clinical Neuroscience 244, 297-303.

Merikangas, K. R., Angst, J., Eaton, W. W., Canino, G., RubioStipec, M., Wacker, H., Wittchen, H.-U., Andrade, L., Essau, C., Whitaker, A., Kraemer, H., Robins, L. N. \& Kupfer, D. J. (1996). Comorbidity and boundaries of affective disorders with anxiety disorders and substance misuse: results of an international task force. British Journal of Psychiatry 168, 58-67.

Noyes, R. Jr., Woodman, C., Garvey, M. J., Cook, B. L., Suelzer, M., Clancy, J. \& Anderson, D. J. (1992). Generalized anxiety disorder vs. panic disorder. Distinguishing characteristics and patterns of comorbidity. Journal of Nervous and Mental Disease 180, 369-379.

Parker, G., Wilhelm, K. \& Asghari, A. (1997). Early onset depression: the relevance of anxiety. Social Psychiatry and Psychiatric Epidemiology 32, 30-7.

Pini, S., Cassano, G. B., Simonini, E., Savino, M., Russo, A. \& Montgomery, S. A. (1997). Prevalence of anxiety disorders comorbidity in bipolar depression, unipolar depression and dysthymia. Journal of Affective Disorders 42, 145-153.

Reich, J., Warshaw, M., Peterson, L. G., White, K., Keller, M., Lavori, P. \& Yonkers, K. A. (1993). Comorbidity of panic and major depressive disorder. Journal of Psychiatric Research 27 (suppl. 1), 23-33.

Schneier, F. F., Johnson, J. \& Hornig, C. D. (1992). Social phobia: comorbidity and morbidity in an epidemiologic sample. Archives of General Psychiatry 49, 282-288.

Simon, G. E. \& VonKorff, M. (1995). Recall of psychiatric history in cross-sectional surveys: implications for epidemiologic research. Epidemiologic Review 17, 221-227.

Sullivan, P. F., Kessler, R. C. \& Kendler, K. S. (1998). Latent class analysis of lifetime depressive symptoms in the National Comorbidity Survey. American Journal of Psychiatry 155, 1398-1406.

Weiller, E., Bisserbe, J. C., Boyer, P., Lepine, J. P. \& Lecrubier, Y. (1996). Social phobia in general medical case: an unrecognized undertreated disabling disorder. British Journal of Psychiatry 168, 169-74.

Wittchen, H.-U. \& Essau, C. A. (1989). Comorbidity of anxiety disorders and depression: does it affect course and outcome? Psychiatry and Psychobiology 4, 315-323.

Wittchen, H.-U. \& Beloch, E. (1996). The impact of social phobia on quality of life. International Clinical Psychopharmacology 11, 15-23.

Wittchen, H.-U., Burke, J. D., Semler, G. \& Pfister, H. (1989). Recall and dating of psychiatric symptoms: test-retest reliability of timerelated symptom questions in a standardized psychiatric interview. Archives of General Psychiatry 46, 437-443.

Wittchen, H.-U., Reed, V. \& Kessler, R. C. (1998). Relationship of agoraphobia and panic in a community sample of adolescents and young adults. Archives of General Psychiatry 55, 1017-1024.

World Health Organization (1990). Composite International Diagnostic Interview (CIDI version 1.0). World Health Organization: Geneva.

World Health Organization (1991). International Classification of Diseases (ICD-10). World Health Organization: Geneva. 